Brown, was that water-wet guncotton could be made to detonate by means of a small primer of dry guncotton, which had in its turn been set off by a mercury fulminate detonator. This arrangement was a considerable advantage from the military point of view, because it meant that the great bulk of the explosive could be transported and stored in a very insensitive form, and only after insertion of the sensitive dry guncotton primer was the material really hazardous, and then only if the primer itself were submitted to shock or friction. The foundations were thus laid for the production and use of guncotton as a military explosive.

During the years that followed, a vast amount of investigation was carried out on the subject of the nitration of cellulose. This work was by no means confined to the possible military applications of nitrocellulose. Every possible aspect of the new chemical was examined and tested, and the result was that an enormous and expanding field of application was found. It soon became apparent to the investigators that the so-called guncotton wes only one of the possible products of nitration of cellulose, and that by varying the conditions of production, a wide range of products could be obtained. All these were, of course, nitrocelluloses, or, more correctly, cellulose nitrates; but they differed from each other in their nitrogen contents, in their solubilities in different solvents and in the viscosities of their solutions. These differences had a profound effect on the applicability of the different types of nitrocelluloses to the numerous uses which were to be discovered.

A range of nitrocelluloses was produced, having nitrogen contents from about 10 per cent to more than 13.4 per cent, and viscosities from a free-flowing 40 per cent solution to a stiff jelly in 3 per cent solution.

The nitrocelluloses were shown to be applicable, not only as military high explosives, but also, in admixture with nitroglycerine, as explosives for commercial blasting and special military applications ; and also for the production of the propellantscordite, nitrocellulose powder and smokeless shotgun powders. These examples are all in the explosives category, but the applications in other industries are no less extensive.

Quite apart from its explosive properties, nitro. cellulose has special characteristics which render it unique in the chemical field. Its outstanding feature is to give, in combination with suitable plasticizers, hard and tough films and plastics. Celluloid consists of nitrocellulose and camphor, and is well known for its resistance to wear and to many chemicals. Nitrocellulose paints and lacquers have established for themselves a high reputation for quality and lasting properties. Leathercloth based on nitrocellulose is well known to be of high quality and reliability. Apart from these uses there are numerous other applications, including varnishes, adhesives and surgical uses.

Mention must also be made of Chardonnet's invention of a so-called artificial silk based on nitrocellulose, solutions of which were spun into fibres, which were then denitrated. His process has, of course, been superseded, but his work laid the foundations of a great and universally beneficial industry.

In this era of progress we leave behind the old and move on to the new, but at the moment the century. old nitroglycerine and military guncotton, with its industrial counterpart, are still well to the fore, and seem likely to remain so.

\section{NUTRITIVE VALUES OF FOODS AND CONDIMENTS $5^{5} /:$}

A $T$ a meeting of the Nutrition Panel of the Food Group of $y$ Society of Chemical Industry at Burlingtgn fousd London, on May 29, four papers. together fovering the nutritive values of vinegar, pickleg condiments, margarine, edible fats, nuts and meat a tractentere read to an appreciative audience. Mr. H. S. Sarson opened by confessing that the att mpt to assess "The Nutritive Value of Vinegar, Pickles and Condiments" put him on the horns of a dilemma : whether to emphasize analysis or cookery. Viewed analytically, the substances seldom show impressive results; nevertheless many are of high nutritive value. Vinegar, for example, is more than a digestive stimulant; it contains phosphorus, nitrogen and the $B$ vitamins. Not only in Roman times; but also until a hundred years ago in Great Britain, fruit vinegars, sometimes flavoured and sweetened, were popular summer drinks.

Pickling, originally a method of preserving summer foods for winter use, was restricted to condimental use with the development of agricultural methods. But even to-day it is difficult to say whether sauerkraut and pickled herring are preserved foods (in both cases the nutritive elements are considerable) or just pickles. The food value of sauces, especially fruit sauces, is obviously high ; normally, however (excepting predatory small boys!), one eats nutritively insignificant quantities per day. Salad creams are in a similar position, although in summer-time the daily intake may assume nutritive importance. Jams and preserves present an inverse example; normally contributing usefully to the diet, they are occasionally used purely as condiments (for example, red currant jelly with roast mutton).

Analytically, then, there is no strong case for the value of pickles, sauces, spices, etc., and deprivation would not cause deficiency diseases. Yet they have what it is not unfair to call essential roles in cooking throughout the world, in so far as a completely ungarnished diet would be grim and monotonous.

There is a curious specificity about "the little more and how much it is', a peculiar 'just rightness' about, for example, chips plus vinegar, or pheasant plus bread sauce (and what is it that 'makes' bread sauce but the smell of onions and the taste of cloves?). Most efforts to alter, extend or shuffle such timehonoured combinations have failed, although new combinations are still being unearthed. Less than twenty-five years ago an American found that the best salad to accompany roast chicken is pineapple. One notes a semblance of orderliness about these combinations; for example, sharp sauces for fatty foods, sweet things with carbohydrates; and the general rule applies, the more highly flavoured the bulk food the stronger must be the condiment. Condiments are best regarded as nutritional catalysts, substances that may be (although by no means invariably) inert in themselves, but the presence of which renders food more appetizing and therefore more beneficial. Their place in the national dietary is of great import. ance.

"The Nutritive Value of Margarine and Edible Vegetable Oils" was then dealt with by Dr. H. Wilkinson, who began by grouping these food materials as follows : (a) oils extracted from oil seeds, then refined and deodorized, (b) the same oils hardened by hydrogenation, (c) blended oils as used in margarine 
and cooking fats. Group (c) may be subdivided into (i) mixtures of a small amount of hardened fat in a preponderance of liquid oil (this yields a creamy product) and (ii) mixtures simulating in texture and analysis some natural product.

The commonest edible oils used in Great Britain are ground-nut, palm kernel, palm, cotton-seed, coco-nut and soya bean. Their nutritive value can be considered either purely in terms of available energy or, additionally, in terms of vitamins and essential fatty acids. If available energy is to be the sole criterion, we must, of course, assume that the diet is complete in all other respects. The controlling factor is then net absorption. Oils in group (a) (above), and moderately hardened oils (m.p. $32-42^{\circ} \mathrm{C}$.), are absorbed to 96-99 per cent, while highly hardened oils (m.p. 46-48 ${ }^{\circ}$ C.) are absorbed to 91-94 per cent. The absorptions of mixed oils are usually the weighted means of those of the components, although certain blended and emulsified mixtures (for example, margarine) are better absorbed than the individual components. The fact that the vegetable oils normally used in Great Britain have net absorption figures higher than 90 per cent is satisfactory, in so far as it is unlikely that less than 10 per cent of unabsorbed fat will cause digestive disorders. The calorific value of all such oils falls within the range $8,100-9,100$ calories per kilo.

Some oils, used more extensively outside Britain, are reported to have digestibilities of less than 90 per cent. Cocoa-butter has been the centre of some controversy in this connexion, figures of below 90 per cent and above 95 per cent having been reported. Finally, there are certain types of hardened oils (not encountered in Britain) with low digestibilities.

Passing on to the other aspects of nutritive value, Dr. Wilkinson said that while the fats under discussion are, on the whole, free of vitamin-A precursors, they are often rich in vitamin E. What are termed. 'essential fatty acids' (linoleic, arachidonic and possibly linolenic acids) are also abundant, although a full account of these factors and of vitamin $\mathrm{E}$ in edible oils is not yet available. Palm oil is in a class by itself, and in certain parts of the world it supplies almost the only source of vitamin-A precursors for humans.

Margarine is, of course, a special case so far as vitamins are concerned, because manufacturers in Britain are bound by law to add 550 I.U. of vitamin A, and 90 I.U. of vitamin D, per ounce.

The seed-like structures known as nuts, began Dr. R. Melville, speaking on their nutritive value, are in general highly nourishing, although detailed analyses are still lacking in many cases. Only some of the better known kinds can be dealt with hore.

Most nuts are principally valuable as sources of oil and protein, but some have starch as their main food reserve. A well-known example is the sweet chestnut, containing 75 per cent starch (all analytical data on nuts are based on dry weight); others are the acorns, the water chestnut, certain water-lily seeds (including those of the sacred lotus of India and the giant Amazon water-lily), the once-popular 'tiger nut' (swellings on the rhizomes of a pan-tropical water sedge), the seeds of certain pines, and the kernels of the maidenhair tree (Ginkgo). Two leguminous seeds, the Yeheb nut and the Bambara ground-nut, also fall into this class.

'Oily' nuts form a larger and more important group. Prominent members are the Juglandaceæ such as walnuts, pecans, hickory and others, con- taining 59-74 per cent fat, and in one instance, the butter-nut, as much as 29 per cent protein. The Rosaceæ (almond, peach, plum, etc.) all contain more than 40 per cent fat and $22-33$ per cent protein. Into the same analytical class come beech nuts (47), Barcelona nuts (67), cashew nuts (47), pistacio nuts (56), many pine nuts (48-79), the Pili nuts (75), Brazil nuts (68), pea-nuts (47), coco-nuts (65) and palm nuts (53)--the bracketed figures give percentage fat. Many of these are also rich in protein-the nuts of the stone pine and pea-nuts containing more than 30 per cent. A few of the Cucurbitaceæ yield edible seeds that may be grouped with the foregoing examples; for example, marrow and melon seeds, containing between 30 and 50 per cent fat, are regularly eaten in China, Africa and elsewhere.

As will be seen from the data, many nuts make an approach to a well-balanced ration so far as protein, fat and carbohydrate are concerned. But so far as vitamin contents are concerned our knowledge is still incomplete. There is evidence that nuts generally are good sources of vitamin $B_{1}$, and probably other members of the B complex. The pecan, pea-nut, and Brazil nut are particularly rich in vitamin $B_{1}$, contents of the order of $10 \mu \mathrm{gm}$. per gram having been recorded. Carotenoids, precursors of vitamin $A$, are present in some nuts, particularly high values (10 I.U. per gm.) being noted in some walnuts.

Walnuts are also conspicuous among the several nuts known to contain vitamin $\mathrm{C}$, because it has been discovered that the vitamin-C content of the mature kernel is low, and that of the immature green fruit exceptionally high. The endocarp, which is embryonic shell, is initially rich in vitamin $\mathrm{C}$, but the potency falls as the shell develops, and it is possible that the woody material of the shell is built up from vitamin-C-like units. The nuts are richest just prior to the hardening of the shell; in this condition they are gathered for pickling, although if they are pickled to blackness the vitamin $\mathbf{C}$ is destroyed. They should therefore be 'green pickled'. More than 1 per cent of vitamin $\mathrm{C}$ by weight has been found in walnuts at the appropriate stage of development.

Drs. A. H. Salway and H. G. Rees introduced their paper on "The Nutritive Value of Meat Ixtract" by recalling that Liebig's original preparation, first marketed about the middle of the nineteenth century, enjoyed considerable popular, but meagre scientific, esteem as a nutrient. The strictures of the experts were of course based on the current belief that nutritive value could be assessed solely in terms of proteins, fats and carbohydrates. It is noteworthy, however, that Liebig himself emphasized the effects of meat extract in promoting the appetite and stimulating the gastric juices. Both these suggestions have since been experimentally substantiated by, for example, Pavlov and, more recently, Fisher and Appleby (J. Lab. Clin. Med., 26, 823; 1941), while the physiological benefits of appetite-promoters such as meat extract have always been recognized by dietitians.

An early claim made for meat extract was its ability to assist muscular effort and to increase stamina. The military hygienists of last century certainly believed in, and acted upon, this claim. Nevertheless, in the absence of scientific evidence, this aspect of meat extract had many opponents. But here again supporting evidence is now accumulating.

Analytically, meat extract is extremely complex, and our knowledge is still incomplete. But the 
available information indicates a variety of nutrients the presence of which goes far to explain many of the early claims. True, the albumoses and allied compounds, constituting about 14 per cent of the material, although supplying first-class protein, are of small quantitative significance in the diet. But the meat bases, creatine, creatinine, carnosine, anserine, purines, glutathiones and others, which together account for nearly 30 per cent of the total, are known to stimulate the flow of gastric secretions, to effect muscle metabolism, and to spare proteins from the task of supplying creatine.

It is, however, the vitamins of the B complex in meat extract that are of especial interest and importance.

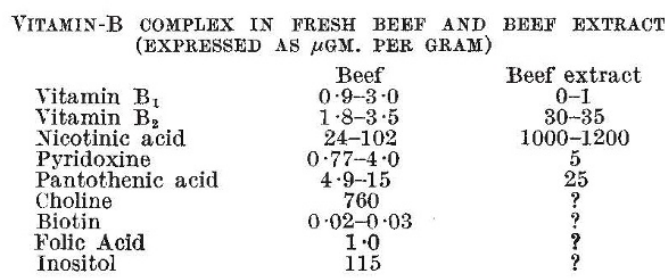

It will be seen that the concentration of many, although not all, of these essential nutrients is high. A few grams of meat extract per day will supply no inconsiderable part of the daily requirements of the B complex. For example, a third or more of the nicotinic acid requirement is contained in 3-4 gm. of meat extract. This, coupled with the fact that nicotinic acid is now known to be concerned with stamina and mental alertness, provides a further instance in vindication of early claims. Finally, the close relation between the $B$ vitamins and a healthy blood picture no doubt explains why meat extract has long been regarded as 'good for the blood'.

A short but interesting discussion followed, the most notable part of which centred on the vitamin-C content of walnuts. The chairman, Mr. A. L. Bacharach, asked Dr. Melville whether the vitamin-C content of walnuts increased significantly during germination, and if so, whether the shell, which Dr. Melville had envisaged as built up from vitamin-Clike molecules, might, in its immature stages, be the source of the vitamin C. In reply, Dr. Melville said that no work on germination had yet been carried out, but the suggestion would be borne in mind.

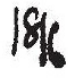

\section{OBITUARIES}

\section{Prof. W.eB. Cannon, For.Mem.R.S.}

Bx the desh on October 2, 1945, of Walter Bradford Cacton, the United States and the world lost ong who, for a whole generation, had been recogniz $d$ as a great leader in his own chosen scientific field of physiology. Cannon was born on October 19 , 1870 at Prairie du Chien, Wis., and received his schooling at Milwaukee and St. Paul, Minn. Entering Harvard in 1892, he remained with that University and its Medical School until his retirement in $\mathbf{1 9 4 2}$ from the chair of physiology, to which he had been appointed in 1906 ; so that his association with Harvard, as student, graduate, instructor and professor, extended over just half a century.

One of Cannon's most practically fruitful discoveries, and the one from which he could trace, in logical sequence, the development of his later interest in other fields of research, was made when he was still a young graduate, beginning research in the Department of $\mathbf{H}$. P. Bowditch, through whom Cannon could claim to be a 'scientific grandson' of Carl Ludwig. Röntgen's discovery of X-rays was a novelty, and Cannon was interested in using them to render visible, on a fluorescent screen, the passage of a metal ball down the cesophagus of a goose. The idea of mixing with food an insoluble bismuth salt, opaque to X-rays, presented itself to Cannon. With this technique he was able to follow the progress of a meal and its products through the alimentary canal of the normal cat; and thus he not only provided invaluable data for the normal physiology of digestion and absorption, but also furnished to medicine and surgery the principle of one of the most powerful items of modern diagnostic equipment.

In these studies on the visceral movements of a normal, un-narcotized cat, Cannon was early struck by the effects on them, and particularly the immediately depressant, inhibitory effect, of emotional excitement-reactions to sudden noises, or to any cause of fright or anger. These observations, in connexion with evidence then coming from other research centres, led Cannon to enter upon a long and fruitful series of researches on the sympathetic nerves and the control by them of the output of adrenaline from the suprarenal medulla, and on the physiological significance of a sudden output of adrenaline into the circulation, as providing favourable physiological conditions for effective flight or combat. The general outcome of this series was summarized by Cannon, for a circle wider than that of the specialists, in a book, now well known, on "Bodily Changes in Pain, Hunger, Fear and Rage".

Through these studies of the physiological concomitants of emotional reactions, Cannon became interested, as Claude Bernard had been before him, in the accuracy with which the mechanisms of adjustment at the disposal of the living body keep such physiological factors as the content of sugar and the alkalinity of the blood at constant average levels, restoring them rapidly thereto after functional fluctuations. Out of such further studies grew another book, of even wider appeal and more broadly philosophical outlook, entitled "The Wisdom of the Body".

In May 1917 Cannon was a member of the Harvard Hospital Unit which arrived, in advance of the American Army, to play its part in the War in France. After working at a casualty clearing station at Bethune, and gaining direct experience of the physiological factors involved in wound shock, he came to England in November of that year, and engaged, in collaboration with the late Sir William Bayliss, in laboratory experiments arising from his observa. tions in the field. Out of this collaborative experience, together with the exchanges and discussions across the table of a Committee on Wound-Shock then sitting in London, came another book by Cannon. Whatever may be the permanence of results thus snatched to meet war's urgent demands, the experience gained, as Cannon himself was later to claim, helped to re-open an attack on such problems when a second world war made its new demand.

Through his studies on sympathetic and adrenal adjustments of bodily function, Cannon was led to his last main series of researches, dealing with the transmission of nervous effects by chemical agents. Observations of the transmission by the blood, to a 